\title{
Téoros
}

Revue de recherche en tourisme

\section{Les régions touristiques de l'Est du Québec : de fascinantes périphéries}

\section{Marc Laplante}

Volume 13, numéro 1, mars 1994

Bas-Saint-Laurent, Gaspésie, Iles-de-la-Madeleine : fascinantes

périphéries

URI : https://id.erudit.org/iderudit/1077766ar

DOI : https://doi.org/10.7202/1077766ar

Aller au sommaire du numéro

\section{Éditeur(s)}

Université du Québec à Montréal

ISSN

0712-8657 (imprimé)

1923-2705 (numérique)

Découvrir la revue

Citer ce document

Laplante, M. (1994). Les régions touristiques de l'Est du Québec : de fascinantes périphéries. Téoros, 13(1), 2-2. https://doi.org/10.7202/1077766ar d'utilisation que vous pouvez consulter en ligne.

https://apropos.erudit.org/fr/usagers/politique-dutilisation/ 


\title{
Présentation \\ Les régions touristiques de l'Est du Québec: de fascinantes périphéries
}

\author{
Marc Laplante
}

Le 19 mai 1993 se tenait, a Rimouski, dans le cadre du 61e Congres de l'Association canadienne-française pour l'avancement des sciences (ACFAS), un colloque organisé par la revue de recherche en tourisme Téoros de l'UQAM ayant pour thème: Le tourisme a la périphérie, l'expérience de la péninsule gaspésienne. Les sousthèmes étaient: espaces touristiques, mise en marché, histoire touristique. L'événementavait été coordonné parles professeurs Velitchko Velikov, Jacques Royet Gilles Brien du département de géographie de l'Université du Québec à Rimouski, le professeur lan Lundgren, géographe de l'université McGill et le professeur Marcel Samson du département d'études urbaines et touristiques de l'Université du Québec à Montréal.

Une trentaine de personnes, en grande majorité de l'Est du Québec, ont participé à cette rencontre. Celle-ci avait été longuement préparée lors de deux réunions d'intervenants du Bas-Saint Laurent et de la Gaspésie au cours de l'hiver 1993. Le présent numéro de Téoros est composé, pour I'essentiel, des textes présentés lors de ce colloque. II contientaussi quelques autres articles, notamment celui des professeurs du Cégep de Matane, mesdames Diane Caron et/sabelle Creusotetmonsieur Alain Turcotte, sur la formation en tourisme etl'action des professionnels en région, celui de madame Yvonne Langford, sur les lles-de-la-Madeleine et celui de monsieur Jean-Claude Jay-Rayon et de madame Brigitte Morneau sur la Baie-des-Chaleurs. Le grand territoire de l'Est du Québec se trouve donc considéré dans les pages de ce numéro.

Comme fil conducteur, l'équipe de Téoros avait suggéré de reprendre le concept de région périphérique, terme souvent employé jusqu'à récemment pour désigner les régions éloignées des centres urbains de Montréal et de Québec. Ce sujet orientait les textes vers la géographie. On constatera rapidement qu'il a guidé les réflexions de plusieurs auteurs, directement ou indirectement. Nous avions souhaité également qu'un effort soit fait pour repenser la notion de région périphérique en l'examinant d'abord comme un fait touristique spécifique porteur de promesses. Certains textes du présent numéro abondent dans ce sens et viendront s'ajouter - nous l'espérons - aux nombreux essais des intervenants del'Est du Québec pour redéfinir leurs territoires - physiques et symboliques - et les développer davantage touristiquement.
Plusieurs des lecteurs ont peut-être deja fait leur wtour de la Gaspésiev. Vont-ils redécouvrir ce grand morceau de pays du Québec en lisant toutes les pages qui suivent? Nous en sommes convaincus. I/s réaliseront sürement q'une volonté tenace anime les intervenants de ces régions, que tous les projets développement touristique se préoccupent autant de fidélité et de protection de l'identité culturelle que des retombées économiques ou encore, que la magie de ces territoires peut toujours jouer sur des visiteurs a la recherche de beauté, de chaleur humaine et d'authenticité. Pour les touristes avertis, les bouts-du-monde sont des paradis : le tourisme dans l'Est du Québec est plein d'avenir. $\boldsymbol{f}$

En page couverture, on voit le Phare de l'Tle-du-Phare, une des îles du Pot-à-l'eau-de-vie, en face de Rivière-du-Loup. Ces îles sont la propriété de la Société Duvetnor vouée à l'interprétation et à la conservation de la nature. Monsieur Jean Bédard, auteur de la photographie, est président de cette société. Celle-ci offre un forfait touristique comprenant une excursion dans les îles, un coucher et un petit déjeuner au Phare (quatre personnes, au maximum). Pour une réservation, on communiquera avec la directrice générale de la Société Duvetnor : Madame Elyse Lauzon au numéro suivant (418-) $867-1660$. 